\title{
Conceptually New Entries into Cells
}

\author{
Javier Montenegro, Charlotte Gehin, Eun-Kyoung Bang, Andrea Fin, David Alonso Doval, \\ Howard Riezman*, Naomi Sakai, and Stefan Matile*
}

\begin{abstract}
This article summarizes the background and a few preliminary results concerning project 7 of the NCCR Chemical Biology. The general objective is to explore new concepts for cellular uptake, membrane tunneling, sensing and labeling. Emphasis is on the use of dynamic covalent chemistry for counterion activation, slow release of polyions and fluorescent probes, and the generation of activator libraries and polyions that grow and shrink.
\end{abstract}

Keywords: Cell-penetrating peptides $\cdot$ Cellular uptake $\cdot$ Sensing $\cdot$ siRNA $\cdot$ Transport

Cellular uptake is a central challenge in chemical biology and beyond. Many wonderful molecules that work in vitro fail in vivo because they simply cannot reach their target. The challenge received recent attention with RNAi because the method is particularly promising but the delivery of siRNA is problematic.. ${ }^{1]}$ Another unresolved challenge concerns uptake into cells where pinocytosis and related routes do not exist or are not accessible.

Arguably the most interesting entry into cells is the direct tunneling through intact membrane barriers, driven by gradients, potentials or, at best, coupled equilibria only. Lessons from viruses have suggested that polycationic, arginine-rich cell-penetrating peptides (CPPs) work this way. ${ }^{[2]}$ However, most mechanistic aspects remain controversial, partially obscure and possibly different with different cells and CPPs. We have argued that much of the confusion concerning 'arginine magic' originates from the role of anionic lipids in cell membranes. ${ }^{[3]}$ From this point of view, cellular uptake of the complementary polyanions such as DNA or RNA is so much easier to understand because cationic lipids are missing in cell membranes. ${ }^{[4]}$

According to the counterion hypothesis, the ability of weakly acidic polycations such as arginine-rich CPPs (1) to enter cells originates from a very general proximity effect (Fig. 1). ${ }^{[3]}$ Namely, the intramolecular repulsion between proximal cat- ions has to be minimized. With more acidic cations such as ammonium (intrinsic $\mathrm{p} K$ $\sim 10.5$ ), this is possible by a reduction of a $\mathrm{p} K$ to release a proton. With the less acidic guanidinium cations, this is excluded (intrinsic $\mathrm{p} K_{\mathrm{a}} \sim 12.5$ ). The only remaining solution to overcome intramolecular charge repulsion is the capture of counterions. As a result, counteranion binding to weakly acidic polycations is very strong, but counterion exchange remains very fast. Polyion-counterion complexes $\mathbf{2}$ are thus very stable thermodynamically and at the same time very labile kinetically. This complex situation is ideal for many activi- ties, including cellular uptake (but terrible for structural studies).

To enter cells, the polyion-counterion complex $\mathbf{2}$ has to exchange the hydrophilic counteranions $\mathrm{X}^{-}$by amphiphilic counterions such as anionic lipids in the membrane or pyrenebutyrate $\mathbf{3}$. The nearly neutral and lipophilic polyion-counterion complex $\mathbf{4}$ can then tunnel through the hydrophobic barrier of the lipid bilayer membrane. For release at the other side, another ion exchange with hydrophilic internal counterions is all that is needed. The driving force for directional translocation is provided either by a chemical gradient or binding to

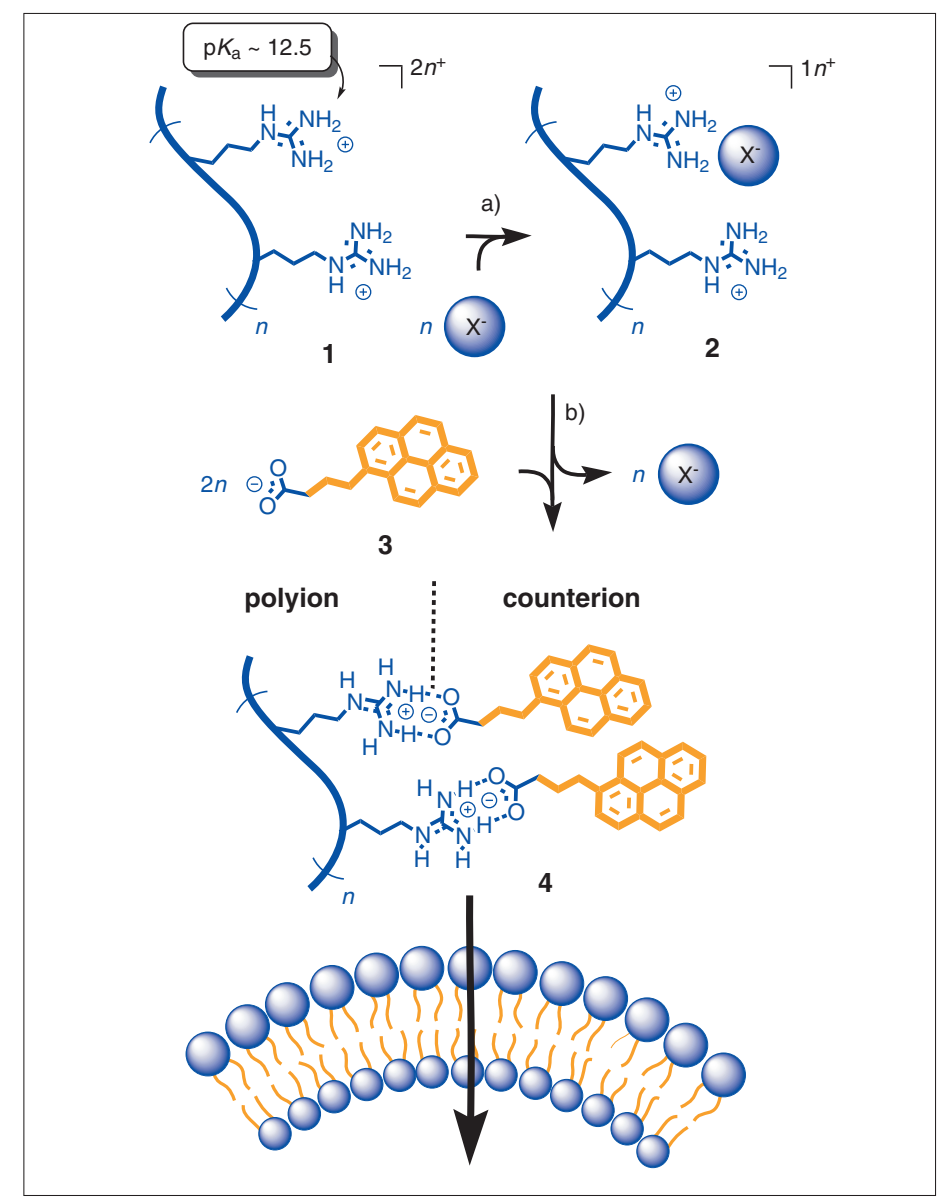

Fig. 1. How do cell-penetrating peptides (CPPs) enter cells? Hydrophobic counteranions are captured by weakly acidic polycation 1 to minimize intramolecular charge repulsion in complex 2. Counterion exchange and charge neutralization with amphiphilic counterions $\mathbf{3}$ gives polyion-counterion complex 4, ready to tunnel through the membrane barrier. 


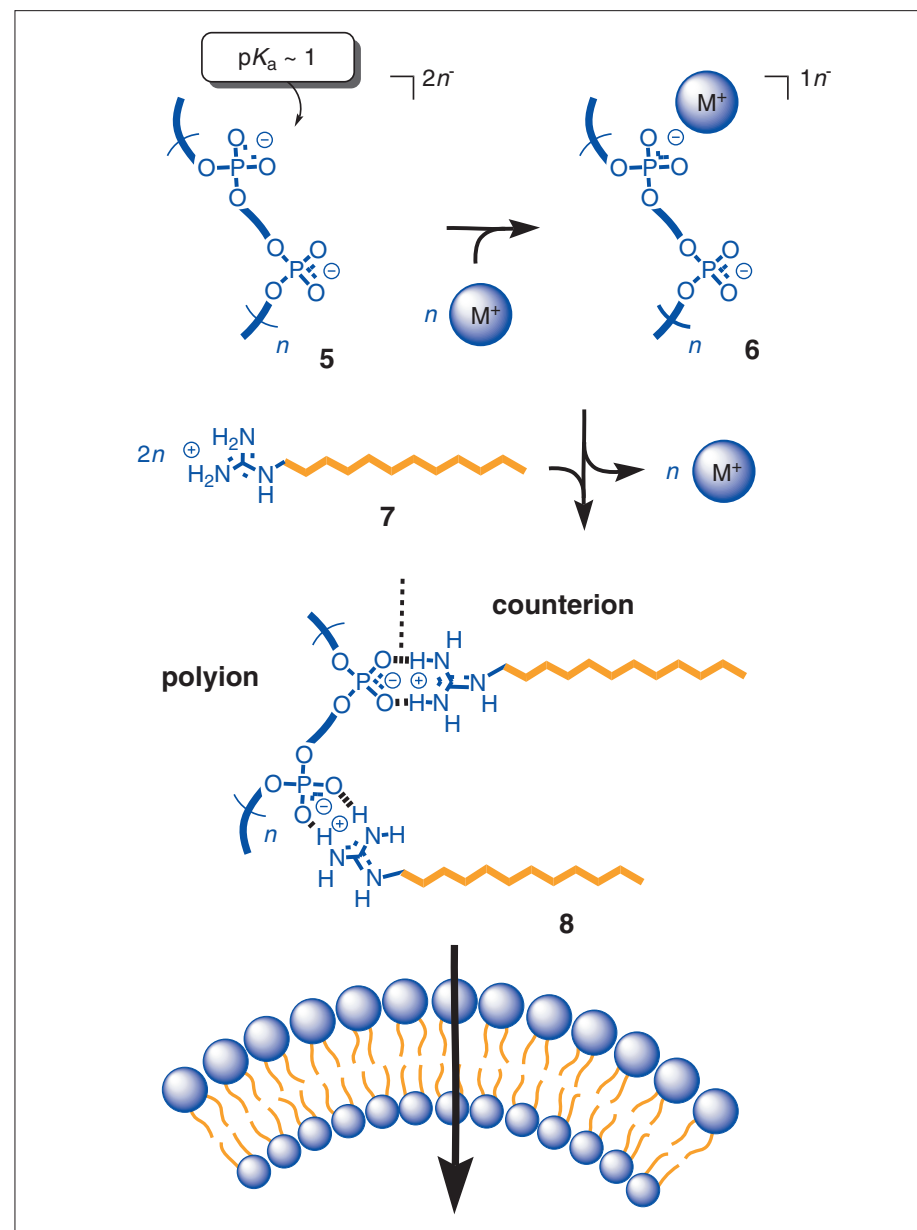

Fig. 2. Full charge inversion in polyion-counterion complexes leads from weakly acidic CPPs 1 (Fig. 1) to weakly basic polyanions such as DNA 5. Activation of the hydrophilic complexes 6 with amphiphilic counteractions such as $\mathbf{7}$ gives hydrophobic polyion-counterion complexes 8 .

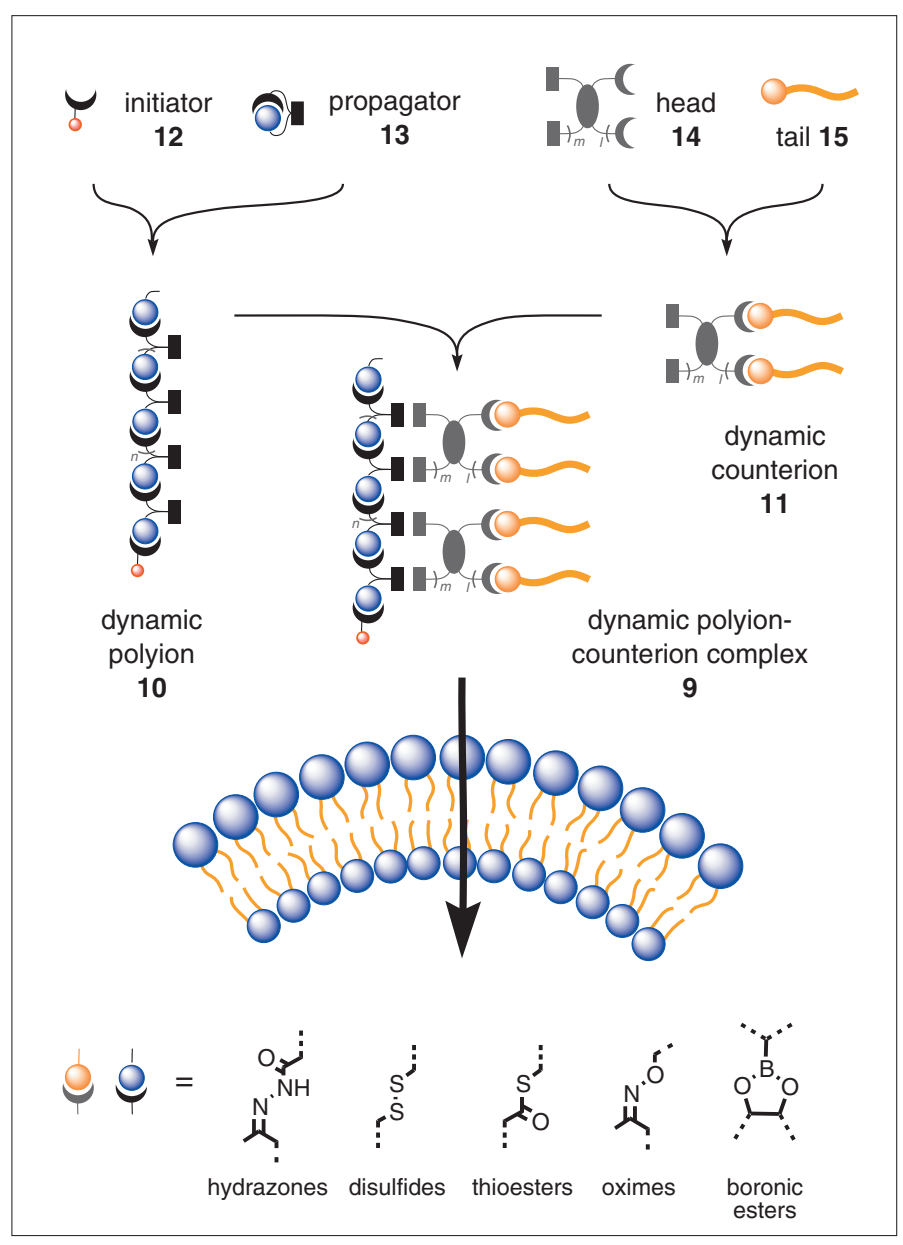

Fig. 3. To harness the power of polyion-counterion complexes, dynamic covalent bonds can be introduced in the polyion and the counterion part. Dynamic polyion-counterion complexes 9 can contain dynamic covalent bonds in polyion $\mathbf{1 0}$, counterions $\mathbf{1 1}$, or both. Dynamic polyions 10 can grow and shrink on initiators 12 before and after use, respectively. Dynamic counterions 11 can form in situ from hydrophilic heads 14 and lipophilic tails 15 and can slowly release both in changing environments. an internal target to shift the coupled equilibria according to Le Chatelier.

The counterion hypothesis has been tested extensively in model systems. ${ }^{[1]}$ Polycations 1 have been shown to dissolve in hydrophobic solvents such as chloroform in the presence of appropriate amphiphilic counterions. Moreover, with the right counterions, polycations $\mathbf{1}$ can phase transfer from water into chloroform (i.e. prefer chloroform over water!) and carry hydrophilic counteranions into and across bulk liquid and intact lipid bilayer membranes.

According to the counterion hypothesis, the introduction of new amphiphilic counteranions for polycations 1 should lead to new functions. To test this idea, a broad variety of anionic amphiphiles has been studied as activators of polycationic anion transporters 1 in both bulk and lipid bilayer membranes. In general, carboxylates were better than phosphates and sulfates; activities increased with multivalency. Aromatic tails were better than aliphatic tails; pyrenebutyrate $\mathbf{3}$, coronene and fullerene de- rivatives were best. Attractive explanations for these trends are easy to formulate but often quite difficult to prove. ${ }^{[3]}$

Complete charge inversion in polyioncounterion transporters was explored to generalize the concept. ${ }^{[5]}$ In this case, only weakly basic polyanions such as phosphodiesters 5 should show powerful counterion effects (Fig. 2). More basic polyanions such as carboxylates should be able to minimize charge repulsion by partial protonation. To move across hydrophobic barriers, the hydrophilic complex $\mathbf{6}$ should exchange with excess amphiphilic counterions such as 7 to give the active, lipophilic and neutral complex 8 .

In agreement with these predictions, counterion-activated DNA was identified as a cation transporter in bulk liquid and intact lipid bilayer membranes, whereas the more basic polyglutamate was inactive. ${ }^{[5]}$ Guanidinium cations were better than ammonium cations; dodecylguanidinium 7 showed good behavior in practical applications.
The finding that amphiphilic cations can activate DNA to move across membranes was not further surprising. Counterion activation is routinely used for gene transfection ${ }^{[4]}$ and siRNA delivery. ${ }^{[1]}$ Different to the situation with CPPs, counterion activation for DNA/RNA uptake is well accepted and developed because intrinsic cationic activators in the membrane that could confuse the picture do not exist. The finding that counterion-activated DNA can also transport cations was perhaps less expected and very interesting for sensing applications with aptamers (see below).

Demonstrating the power of polyioncounterion systems to generate and modulate function in membranes, these results called for practical applications. To gain flexibility, speed and functional diversity, the introduction of dynamic covalent bonds into either the polyion or counterion was considered first (Fig. 3). ${ }^{[6-11]}$ Much stronger than weak interactions such as hydrogen bonds, cation $-\pi$ or $\pi-\pi$ interactions, dynamic covalent bonds still can form 


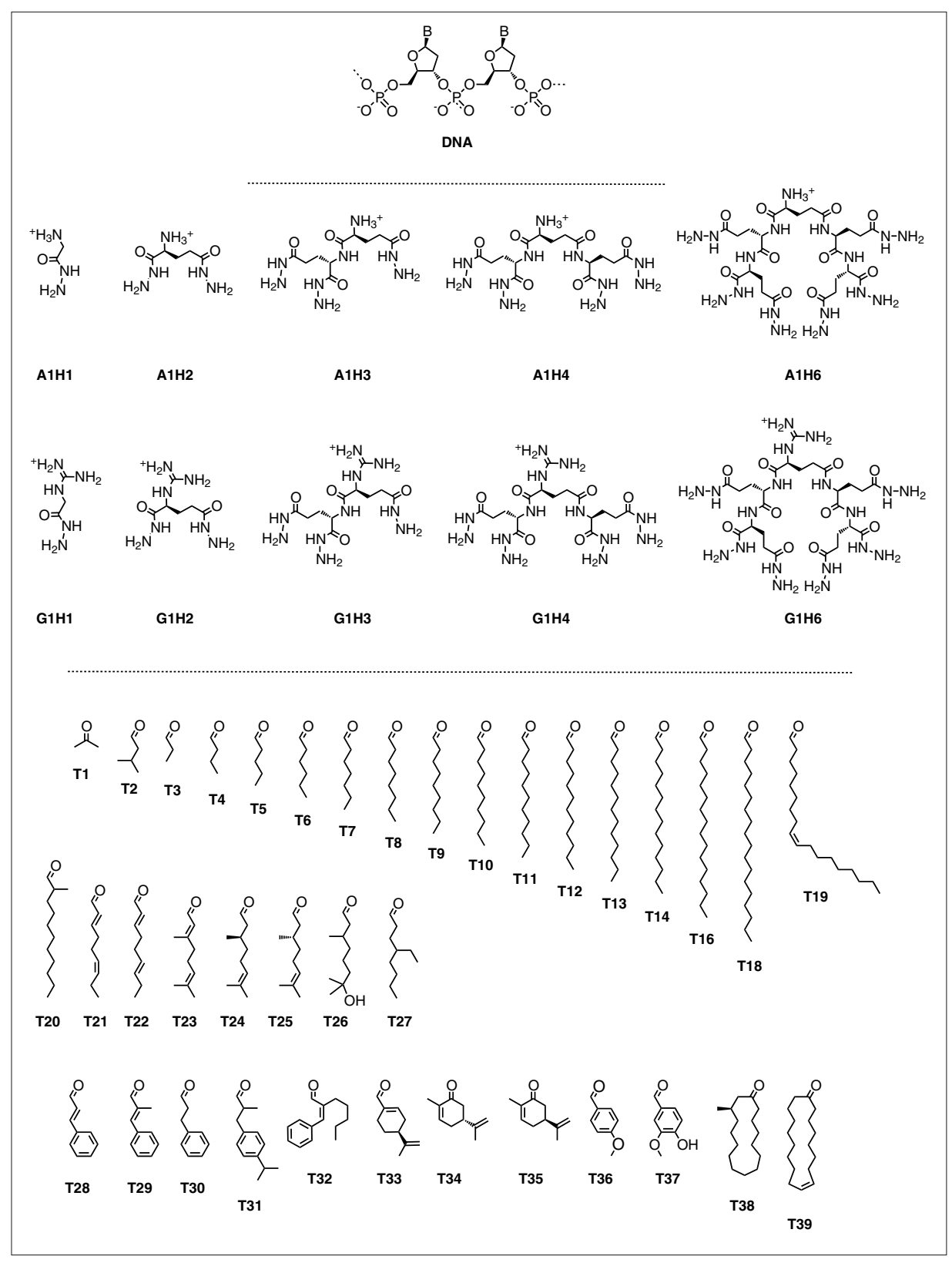

Fig. 4. Structure of reactive heads and tails used to prepare 390 dynamic counterion activators of DNA transporters in fluorogenic vesicles (B stands for nucleobase).

and break reversibly in situ with kinetics depending on the environment. Examples include disulfide exchange, ${ }^{[11]}$ extensively known from protein folding, or hydrazones or oximes; ${ }^{[12]}$ the more stable analogs of the imines known from the chemistry of vision; $[13]$ the red-fluorescent protein; $[14]$ or many reactive intermediates in enzymes such as aldolases, transaminases, or decarboxylases. ${ }^{[15]}$ Dynamic thioester exchange is essential in polyketide synthesis ${ }^{[16]}$ and popular in native chemical ligation and more, ${ }^{[17]}$ boronic esters exemplify dynamic covalent bonds that are rare in biology. ${ }^{[18]}$

Dynamic polyion-counterion complexes 9 can contain dynamic covalent bonds in either polyion $\mathbf{1 0}$, counterion $\mathbf{1 1}$, or both. Dynamic polyions $\mathbf{1 0}$ are of interest because they can grow before and shrink after use in situ on an initiator $\mathbf{1 2}$ of choice by ring-opening polymerization of appropriate propagators 13. Dynamic counterions 11 can form in situ from hydrophilic heads $\mathbf{1 4}$ and hydrophobic tails $\mathbf{1 5}$ and can slowly release both in changing environments. Current efforts concerning dynamic polyions 10 focus on surface-initiated polymerization of artificial photosystems by ring-opening disulfide exchange on transparent and conducting oxide surfaces. ${ }^{[6]}$ Scope and limitations of dynamic counterions $\mathbf{1 1}$ are currently being explored in lipid bilayer membranes. ${ }^{[7-10]}$

To elaborate on dynamic counterions 11, initial emphasis was on hydrazones. ${ }^{[7-10]}$ Peptide dendrons were selected as modular scaffolds and equipped with different numbers of charges and hydrazides (Fig. 4). To activate polyanions such as DNA or RNA, guanidinium (G) and ammonium cations (A) were combined with increasing numbers of reactive hydrazides $(\mathbf{H})$ and tested after incubation with 39 different aldehydes or ketones T1-T39. For example, peptide $\mathbf{G 1 H 3}$, composed of a head group with one guanidinium cation (G1) and three reactive hydrazides (H3), was incubated with jasmine aldehyde T32 (Fig. 5). The resulting dynamic counterion G1H3T32 was added to fluorogenic liposomes, and the ability to activate DNA as cation transporter was determined.

The results of this initial screen were as follows. ${ }^{[8]}$ Guanidinium cations were always better than ammonium cations. Activities increased with increasing number of hydrazones until 'octopus amphiphiles' with three (i.e. G1H3T) to four tails (i.e. G1H4T) but decreased with an excessive number of six 'tentacles' (i.e. G1H6)

With linear alkyl tails, maximal activities were found at intermediate length. With increasing number of tails, maximal activities shifted toward shorter tails. For instance, $\mathbf{G 1 H 2}$ was active with T8-T16, G1H3 with T7-T12, G1H4 with T6-T12 and G1H6 with T5-T7. ${ }^{[8]}$ These trends suggested that polyion-counterion complexes of intermediate hydrophobicity are best. Too lipophilic systems tend to precipitate or to disappear in the middle of the membrane, whereas too hydrophilic systems fail to partition into the membrane. Disorganizing cis-double bonds activated longer alkyl tails such as T19. Overall best activities were obtained with branched aromatic tails as in cyclamen aldehyde T31 and jasmine aldehyde T32. These hits were not predictable from the literature and highlighted the importance of rapid access to large libraries for screening. With the 10 heads and 39 tails made and used for these preliminary studies, a library of 390 different activators became available without significant synthetic effort.

To explore charge inversion with dynamic counterions, head groups with one to three carboxylate $(\mathbf{C})$, phosphonate $(\mathbf{P})$ or sulfonate (S) were prepared (Fig. 6). ${ }^{[9,10]}$ Their ability to activate CPP transporters in fluorogenic vesicles was determined after incubation with a focused collection of lipophilic tails. As with the complementary cations, the planar carboxylates were more potent than the tetrahedral phosphonates. Contrary to the complementary cations, activities did not increase with increasing number of tails. $\mathbf{C 1 H 3}$ was nearly inactive with all tested tails, whereas $\mathbf{G 1 H 3}$ was the best. An excess of charges compared to tails as in C3H1 was not successful either. Best results were obtained with gemini amphiphiles generated with $\mathbf{C 2 H 2}$.

As far as applications are concerned, dynamic polyion-counterion transporters have been ideal to build sensing systems 


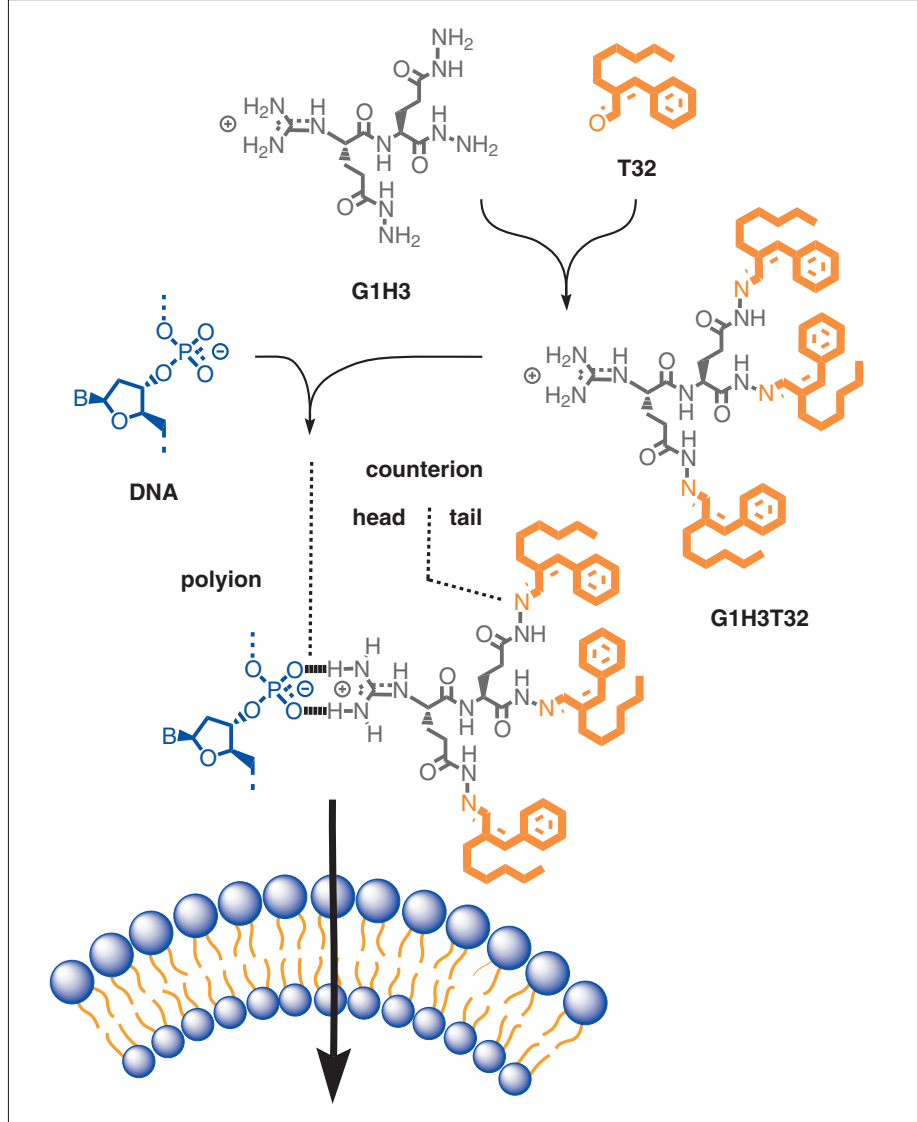

Fig. 5. Example of a dynamic polyion-counterion complex, made by incubation of head G1H3 and jasmine aldehyde tail T32 followed by addition of the dynamic counterion G1H3T32 and DNA to fluorogenic vesicles to determine the transport activity of the final complex.

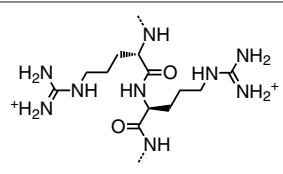

CPP

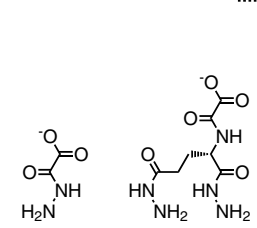

C1H1

C1H2

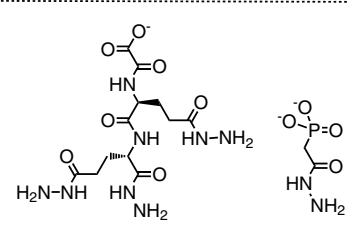

C1H3

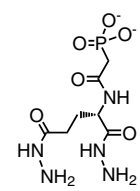

P1H2

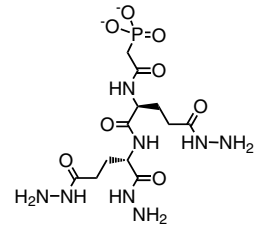

P1H3

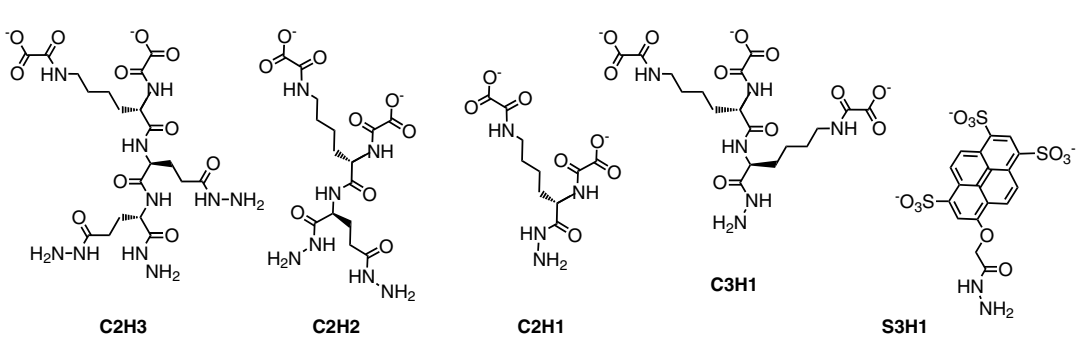

$\mathrm{C} 2 \mathrm{H} 3$

$\mathrm{C2H} 2$

C2H1

S3H1

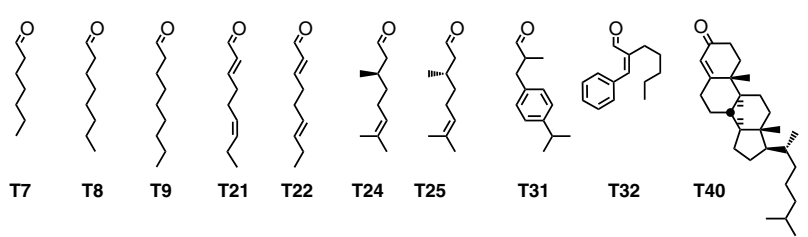

Fig. 6. Structure of reactive heads and tails used to prepare dynamic counterion activators of CPPs as anion transporters in fluorogenic vesicles. that operate, like the mammalian olfactory systems, in lipid bilayer membranes.[7] Compatibility with the three principal sensing methods, that is biosensing, ${ }^{[9]} \mathrm{im}$ munosensing ${ }^{[19]}$ and differential sensing, ${ }^{[7]}$ has been confirmed. Biosensing has been illustrated with a cholesterol sensor.[9] Cholesterol oxidase as analyte-specific signal generator produced cholestenone T40, which was incubated with $\mathbf{S 3 H 1}$ to give the dynamic counterion S3H1T40, which activated CPP transporters in fluorogenic vesicles. Cholesterol levels in egg, caviar and blood serum were correctly detected by this biosensing method. A similar approach has been developed to detect hyaluronan and the activity of hyaluronidase with CPPs. ${ }^{[20]}$

Charge inversion of polyion-counterion complexes has been essential to realize the aptamer version of immunosensing in lipid bilayer membranes. ${ }^{[19]}$ Aptamers are short single-stranded DNAs that, like antibodies, can in principle be generated against virtually any analyte of choice. ${ }^{[21]}$ However, the preparation of aptamers is much easier because DNA biotechnology methods can be used in vitro. For 'aptamerosensing' in lipid bilayers, counterion-activated DNA transporters were ideal to unify signal generation and signal transduction. However, aptamers are short, single-stranded DNA that are not very active as counterion-activated cation transporters in fluorogenic vesicles. With activities increasing with the number of charges per supramolecule, the problem was addressed first with aptamer-antiaptamer duplexes that disassemble during analyte binding. Even better results could be obtained by polymerization of these duplexes with sticky-end technology. The resulting supramolecular polymers excelled as counterion-activated transporters with superb activity and were cleanly disassembled into inactive singlestranded oligomers in response to analyte recognition.

Biosensors and aptamerosensors are ideal to monitor specific analytes that are essential in diagnostics. However, the sensing of $>10^{\prime} 000$ odorants by 350 signal generators as in our olfactory system will never be possible with these methods.[22] Differential sensing approaches for pattern generation and pattern recognition are the only way to tackle this challenge. Very popular in many other systems, ${ }^{[23]}$ differential sensing has not been possible so far in lipid bilayer membranes. However, with the introduction of dynamic counterion activators, pattern generation became possible. To sense odorants such as jasmine aldehyde T32, capture by G1H3 and DNA activation with the resulting G1H3T32 will give three characteristic values (Fig. 5). The combination of jasmine aldehyde with all ten heads available for DNA activation 


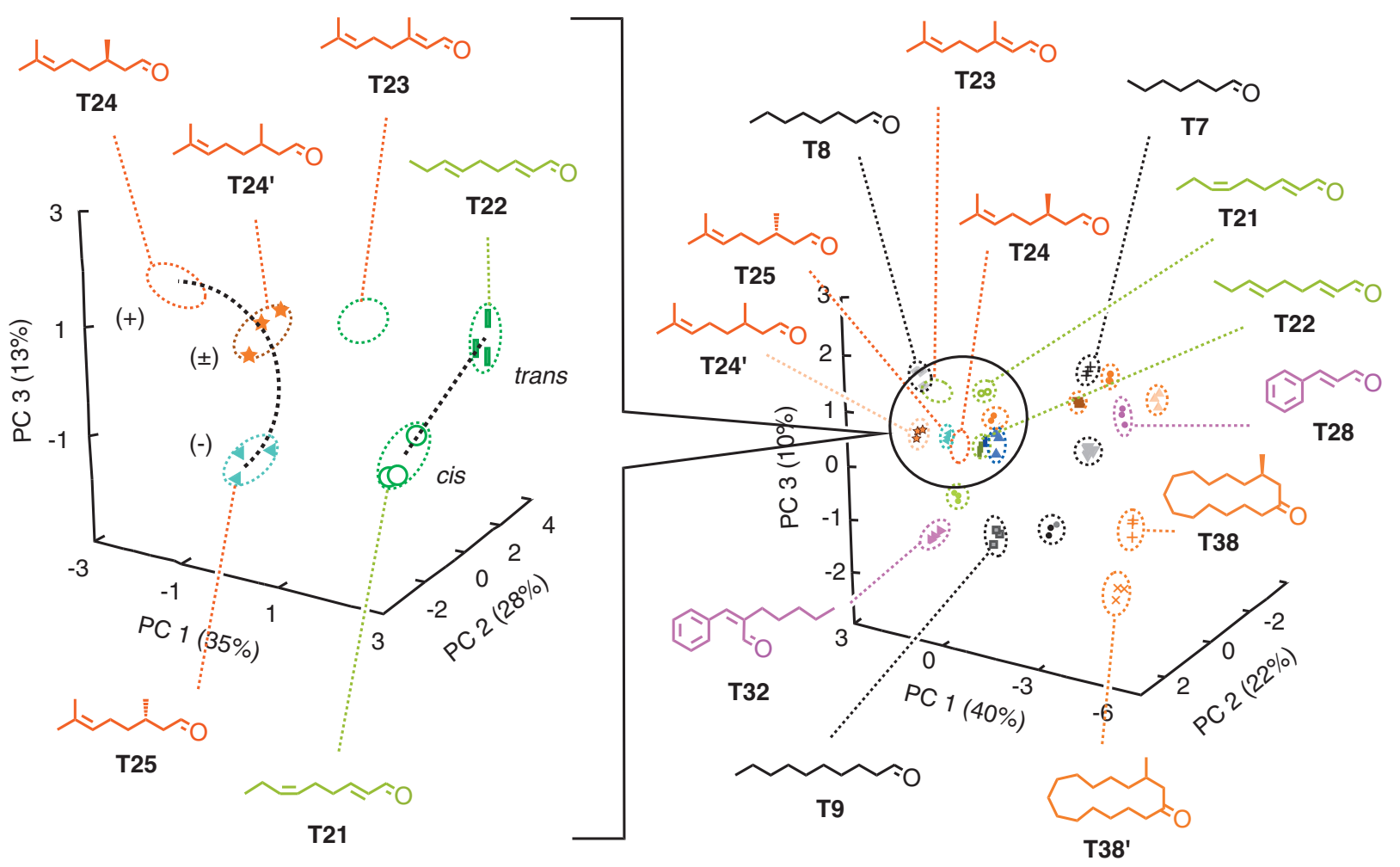

Fig. 7. Dynamic polyion-counterion complexes as differential sensing systems. In global principal component analysis (PCA) score plots, PC 1 - PC 3 describe the first three principal components. The comparably low percentage of data variance covered is good because it indicates that many complementary interactions contribute to analyte discrimination. Each data point represents and independent experiment with DNA polyions and counteranions G1H3, G1H2, A1H3 and $\mathbf{A} 1 \mathbf{H} 3$ (Fig. 4). The global PCA score plot on the right indicates overlap-free discrimination of 21 odorants. Apparent clusters are readily resolved in focused PCA score plots (right). This includes enantiodiscrimination and cis-trans isomerization (Adapted with permission from reference [7], copyright 2011 Royal Society of Chemistry.

will rapidly afford a 30-dimensional pattern characteristic for this analyte (Fig. 4). Routine principal component (PC) analysis revealed that already 12 -dimensional patterns generated with G1H3, G1H2, A1H3 and $\mathbf{A 1 H 2}$ are sufficient to discriminate more than 20 different odorants (Fig. 7). This includes structurally closely related analytes such as single-carbon homologs, cis-trans isomers or enantiomers of the 'Geneva odorant' muscone ${ }^{[24]}$ and citronellal. Apparent clusters in global PC score plots were readily separated in focused plots (Fig. 7, left). The same differential sensing system discriminated successfully all tested perfumes. ${ }^{[7]}$ Moreover, charge inversion for differential sensing with CPPs was no problem. ${ }^{[10]}$

As far as cellular uptake is concerned, CPPs can be activated by the anionic lipids in biomembranes. Considering that intrinsic counteranions presumably account for function on the one hand but complicate results on the other hand, we concluded that the addition of counterion activators should make CPPs really and reliably penetrate cell. ${ }^{[3]}$ This speculation turned out to be correct. ${ }^{[25]}$ Pyrenebutyrate $\mathbf{3}$ was found to mediate the rapid cytosolic delivery of CPPs (Fig. 1). This counterion activator was interpreted to function like a catalyst for translocation, accelerating the movement across biomembranes and thus kinetically outcompeting the otherwise dominant pinocytosis. ${ }^{[3,5]}$

Dynamic polyion-counterion complexes are expected to provide the flexibility to find conceptually new approaches to deliver polyanions such as siRNA and polycations such as CPPs into cells. Dynamic counterions provide facile access to significant libraries. Already with the 10 heads and 39 tails in Fig. 4, 390 counterion activators can be produced with little effort. Screening of this library for siRNA uptake into HeLa cells is ongoing. Preliminary results are promising; the structure of the so far most powerful transporters could by no means have been predicted by rational design. Equipment installed and collaborations developed in the context of the NCCR Chemical Biology are ideal to accelerate and broaden screening assays to fully exploit the unique opportunity to find new routes into different cells.

Another important characteristic of dynamic polyion-counterion complexes is that they will slowly depolymerize or re- lease their tails, with kinetics depending on the environment. Slow release of odorant tails will result in fragrant delivery. Current objectives with slow tail release include the modification of uptake mechanisms. For example, liberated tails could be involved in facilitating the translocation across plasma or endosomal membranes. Moreover, the slow release of fluorescent tails will be of interest for the targeted labeling of intracellular membranes. New fluorescent probes that report on membrane polarization, fluidity and homogeneity are of particular interest for this purpose. [26]

In summary, experimental evidence has been collected in support of polyioncounterion complexes as a universal motif to generate and modulate function in biomembranes in the broadest sense. Realized examples include transport, biosensing, aptamerosensing as well as cellular uptake of DNA, RNA and CPPs. Preliminary results on the introduction of dynamic bonds in polyion-counterion complexes demonstrate facile access to large libraries to screen for various activities, including cellular uptake. Applicability to differential sensing is confirmed with the creation of 
an artificial nose that works, like our olfactory systems, in lipid bilayer membranes. Current studies focus on the screening of dynamic counterion libraries for siRNA delivery into different cells, the introduction of various fluorescent tails for the targeted labeling of membrane domains, and the study of dynamic polyions on solid surfaces, in model membranes and in cells. Preliminary results are very encouraging.

\section{Acknowledgements}

We warmly thank all past and present coworkers and collaborators for their contributions to this research, and the NCCR Chemical Biology, the Swiss NSF, the University of Geneva and the European Research Council (ERC Advanced Investigator) for financial support. We particularly thank S. Futaki and T. Takeuchi for very important contributions.

Received: August 25, 2011

[1] a) S. C. Semple, A. Akinc, J. Chen, A. P. Sandhu, B. L. Mui, C. K. Cho, D. W. Y. Sah, D. Stebbing, E. J. Crosley, E. Yaworski, I. M. Hafez, J. R. Dorkin, J. Qin, K. Lam, K. G. Rajeev, K. F. Wong, L. B. Jeffs, L. Nechev, M. L. Eisenhardt, M. Jayaraman, M. Kazem, M. A. Maier, M. Srinivasulu, M. J. Weinstein, Q. Chen, R. Alvarez, S. A. Barros, S. De, S. K. Klimuk, T. Borland, V. Kosovrasti, W. L. Cantley, Y. K. Tam, M. Manoharan, M. A. Ciufolini, M. A. Tracy, A. de Fougerolles, I. MacLachlan, P. R. Cullis, T. D. Madden, M. J. Hope, Nat. Biotechnol. 2010, 28, 172; b) M. Mével, N. Kamaly, S. Carmona, M. H. Oliver, M. R. Jorgensen, C. Crowther, F. H. Salazar, P. L. Marion, M. Fujino, Y. Natori, M. Thanou, P. Arbuthnot, J.-J. Yaouanc, P. A. Jaffrès, A. D. Miller, J. Controlled Release 2010, 143, 222; c) M. E. Davis, J. E. Zuckerman, C. H. J. Choi, D. Seligson, A. Tolcher, C. A. Alabi, Y. Yen, J. D. Heidel, A. Ribas, Nature 2010, 464, 1067; d) T. Musacchio, O. Vaze, G. D'Souza, and V. P. Torchilin, Bioconjugate Chem. 2010, 21, 1530.

[2] a) I. Mäger, E. Eiríksdóttir, K. Langel, S. E. Andaloussi, Ü. Langel, Biochim. Biophys. Acta 2010, 1798, 338; b) K. Inomata, A. Ohno, H. Tochio, S. Isogai, T. Tenno, I. Nakase, T. Takeuchi, S. Futaki, Y. Ito, H. Hiroaki, M. Shirakawa, Nature 2009, 458, 106; c) E. S. Olson, T. A. Aguilera, T. Jiang, L. G. Ellies, Q. T. Nguyen, E. H. Wong, L. A. Gross, R. Y. Tsien, Integr. Biol. 2009, 1, 382; d) E. K. Esbjorner, P. Lincoln, B. Norden, Biochem. Biophys. Acta 2007, 1768, 1550; e) T. Shimanouchi, P. Walde, J. Gardiner, Y. R. Mahajan, D. Seebach, A. Thomae, S. D. Kraemer, M. Voser, R. Kuboi, Biochem. Biophys. Acta 2007, 1768, 2726; f) M. Martinell, X. Salvatella, J. FernándezCarneado, S. Gordo, M. Feliz, M. Menéndez, E. Giralt, ChemBioChem 2006, 7, 1105; g) D. Schmidt, Q. X. Jiang, R. MacKinnon, Nature 2006, 444, 775; h) J. B. Rothbard, T. C. Jessop, R. S. Lewis, B. A. Murray, P. A. Wender, J. Am. Chem. Soc. 2004, 124, 9506.

[3] a) F. Perret, M. Nishihara, T. Takeuchi, S. Futaki, A. N. Lazar, A. W. Coleman, N. Sakai, S. Matile, J. Am. Chem. Soc. 2005, 127, 1114; b) M. Nishihara, F. Perret, T. Takeuchi, S. Futaki, A. N. Lazar, A. W. Coleman, N. Sakai, S. Matile, Org. Biomol. Chem. 2005, 3, 1659; c) N. Sakai, T. Takeuchi, S. Futaki, S. Matile, ChemBioChem 2005, 6, 114; d) N. Sakai, S. Matile, J. Am. Chem. Soc. 2003, 125, 14348.

[4] a) J. A. Boomer, M. M. Qualls, H. D. Inerowicz, R. H. Haynes, V. S. Patri, J. M. Kim, D. H.
Thompson, Bioconjugate Chem. 2009, 20, 47; b) S. Bhattacharya, A. Bajaj, Chem. Commun. 2009, 45, 4632; c) J. Yang, H. Chen, I. R. Vlahov, J. X. Cheng, P. S. Low, J. Pharmacol. Exp. Ther. 2007, 321, 462; d) H. Isobe, W. Nakanishi, N. Tomita, S. Jinno, H. Okayama, E. Nakamura, Chem. Asian J. 2006, 1, 167; e) M. Sainlos, M. Hauchecorne, N. Oudrhiri, S. Zertal-Zidani, A. Aissaoui, J.-P. Vigneron, J.-M. Lehn, P. Lehn, ChemBioChem 2005, 6, 1023; f) A. J. Kirby, P. Camilleri, J. B. F. N. Engberts, M. C. Feiters, R. J. M. Nolte, O. Söderman, M. Bergsma, P. C. Bell, M. L. Fielden, C. L. García Rodríguez, P. Guédat, A. Kremer, C. McGregor, C. Perrin, G. Ronsin, M. C. P. van Eijk, Angew. Chem. Int. Ed. 2003, 42, 1448; g) D. A. Tomalia, A. M. Naylor, W. A. Goddard, Angew. Chem. Int. Ed. 1990, 29, 138; h) P. L. Felgner, T. R. Gadek, M. Holm, R. Roman, H. W. Chan, M. Wenz, J. P. Northrop, G. M. Ringold, M. Danielsen, Proc. Natl. Acad. Sci. USA 1987, 84, 7413.

[5] a) T. Takeuchi, N. Sakai, S. Matile, Faraday Disc. 2009, 143, 187; b) T. Takeuchi, V. Bagnacani, F. Sansone, S. Matile, ChemBioChem 2009, 10, 2793.

[6] a) N. Sakai, M. Lista, O. Kel, S. Sakurai, D. Emery, J. Mareda, E. Vauthey, S. Matile, J. Am. Chem. Soc. 2011, 133, 15224; b) M. Lista, J. Areephong, N. Sakai, S. Matile, J. Am. Chem. Soc. 2011, 133, 15228.

[7] T. Takeuchi, J. Montenegro, A. Hennig, S. Matile, Chem. Sci. 2011, 2, 303.

[8] a) J. Montenegro, P. Bonvin, T. Takeuchi, S. Matile, Chem. Eur. J. 2010, 16, 14159; b) J. Montenegro, A. Fin, S. Matile, Org. Biomol. Chem. 2011, 9, 2641.

[9] S. M. Butterfield, T. Miyatake, S. Matile, Angew. Chem. Int. Ed. 2009, 48, 325.

[10] J. Montenegro, S. Matile, Chem. Asian J. 2011, 6,681 .

[11] a) Corbett, J. Leclaire, L. Vial, K. R. West, J. L. Wietor, J. K. M. Sanders, S. Otto, Chem. Rev. 2006, 106, 3652; b) F. B. L. Cougnon, H. Y. Au-Yeung, G. D. Pantos, J. K. M. Sanders, J. Am. Chem. Soc. 2011, 133, 3198; c) J. M. A. Carnall, C. A. Waudby, A. M. Belenguer, M. C. A. Stuart, J. J.-P. Peyralans, S. Otto, Science 2010, 327, 1502; d) R. Singh, G. M. Whitesides, J. Am. Chem. Soc. 1990, 112, 1190; e) A. Sadownik, J. Stefely, S. L. Regen, J. Am. Chem. Soc. 1986, 108, 7789

[12] a) O. Ramström, J.-M. Lehn, Nat. Rev. Drug Discov. 2002, 1, 26; b) A. Herrmann, Org. Biomol. Chem. 2009, 7, 3195; c) M. von Delius, E. M. Geertsema, D. A. Leigh, Nat. Chem. 2010, 2, 96.

[13] B. Borhan, M. L. Souto, H. Imai, Y. Shichida, K. Nakanishi, Science 2000, 288, 2209.

[14] R. Y. Tsien, Angew. Chem. Int. Ed. 2009, 48, 5612.

[15] a) L. Jiang, E. A. Althoff, F. R. Clemente, L. Doyle, D. Röthlisberger, A. Zanghellini, J. L. Gallaher, J. L. Betker, F. Tanaka, C. F. Barbas III, D. Hilvert, K. N. Houk, B. L. Stoddard, D. Baker, Science 2008, 319, 1387; b) M. M. Müller, M. A. Windsor, W. C. Pomerantz, S. H. Gellman, D. Hilvert, Angew. Chem. Int. Ed. 2009, 48, 922; c) T. D. Machajewski, C.-H. Wong, Angew. Chem. Int. Ed. 2000, 39, 1352; d) M. Movassaghi, E. N. Jacobsen, Science 2002, 298, 1904; e) C. M. Tann, D. Qi, M. D. Distefano, Curr. Opin. Chem. Biol. 2001, 5, 696; f) K. Johnsson, R. K. Allemann, H. Widmer, S. A. Benner, Nature 1993, 365, 530.

[16] a) C. Khosla, J. Org. Chem. 2009, 74, 6416; b) T. Maier, M. Leibundgut, D. Boehringer, N. Ban, Q. Rev. Biophys. 2010, 43, 373.

[17] a) S. B. H. Kent, Chem. Soc. Rev. 2009, 38, 338; b) Y. Ura, M. Al-Sayah, J. Montenegro, J. Beierle, L. Leman, M. R. Ghadiri, Org. Biomol. Chem. 2009, 7, 2878; c) J. L. Price,
E. B. Hadley, J. D. Steinkruger, S. H. Gellman, Angew. Chem. Int. Ed. 2010, 49, 368.

[18] a) R. Nishiyabu, Y. Kubo, T. D. James, J. S. Fossey, Chem. Commun. 2011, 47, 1124; b) C. M. Bromba, P. Carrie, J. K. W. Chui, T. M. Fyles, Supramol. Chem. 2009, 21, 81; c) K. Severin, Dalton Trans. 2009, 5254; d) A. Hennig, S. Hagihara, S. Matile, Chirality 2009, 21, 826; e) S. Hagihara, H. Tanaka, S. Matile, J. Am. Chem. Soc. 2008, 130, 5656; f) N. Y Edwards, T. W. Sager, J. T. McDevitt, E. V. Anslyn, J. Am. Chem. Soc. 2007, 129, 13575; g) H. M. El-Kaderi, J. R. Hunt, J. L. MendozaCortés, A. P. Côté, R. E. Taylor, M. O’Keeffe, O. M. Yaghi, Science 2007, 316, 268.

[19] T. Takeuchi, S. Matile, J. Am. Chem. Soc. 2009, 131, 18048.

[20] T. Miyatake, M. Nishihara, S. Matile, J. Am. Chem. Soc. 2006, 128, 12420.

[21] a) A. D. Ellington, J. W. Szostak, Nature 1990, 346, 818; b) C. Tuerk, L. Gold, Science 1990, 249, 505; c) Z. Cao, R. Tong, A. Mishra, W. Xu, G. C. Wong, J. Cheng, Y. Lu, Angew. Chem. Int. Ed. 2009, 48, 6494; d) N. Lin, J. Yan, Z. Huang, C. Altier, M. Li, N. Carrasco, M. Suyemoto, L. Johnston, S. Wang, Q. Wang, H. Fang, J. CatonWilliams, B. Wang J. Am. Chem. Soc. 2008, 130, 12636; e) I. Willner, M. Zayats, Angew. Chem. 2007, 119, 6528.

[22] L. B. Buck, Angew. Chem. Int. Ed. 2005, 44, 6128.

[23] a) S. H. Lim, L. Feng, J. W. Kemling, C. J Musto, K. S. Suslick, Nature Chem. 2009, 1, 562 ; b) P. Anzenbacher Jr, P. Lubal, P. Bucek, M. A. Palacios, M. E. Kozelkova, Chem. Soc. Rev. 2010, 39, 3954; c) L. A. Joyce, S. H. Shabbir, E. V. Anslyn, Chem. Soc. Rev. 2010, 39, 3621; d) J. J. Lavigne, E. V. Anslyn, Angew. Chem. Int. Ed. 2001, 40, 3118; e) A. Buryak, K. Severin, Angew. Chem. Int. Ed. 2005, 44, 7935.

[24] L. Ruzicka, Helv. Chim. Acta 1926, 9, 715.

[25] T. Takeuchi, M. Kosuge, A. Tadokoro, Y. Sugiura, M. Nishi, M. Kawata, N. Sakai, S. Matile, S. Futaki, ACS Chem. Biol. 2006, 1, 299.

[26] a) O. A. Kucherak, S. Oncul, Z. Darwich, D. A. Yushchenko, Y. Arntz, P. Didier, Y. Mely, A. S. Klymchenko, J. Am. Chem. Soc. 2010, 132, 4907; b) H. M. Kim, B. R. Cho, Acc. Chem. Res. 2009, 42, 863; c) P. Yan, A. Xie, M. Wei, L. M. Loew, J. Org Chem. 2008, 73, 6587; d) T. Baumgart, G. Hunt, E. R. Farkas, W. W. Webb, G. W. Feigenson, Biochim. Biophys. Acta 2007, 1768, 2182; e) L. A. Bagatolli, L. A. Biochim. Biophys. Acta 2006, 1758, 1541. 